\title{
Adventitious Juice Vesicles Produced from the Exocarp in the Citrinae (Aurantioideae)
}

\author{
Brent Tisserat ${ }^{1}$ and Paul D. Galletta ${ }^{2}$ \\ Fruit and Vegetable Chemistry Laboratory, Agricultural Research \\ Service, U.S. Department of Agriculture, 263 South Chester Avenue, \\ Pasadena, CA 91106 \\ Additional index words. citrus, endocarp, flavedo, juice sacs, oil glands, peel, pulp, \\ Rutaceae
}

\begin{abstract}
Some cultivars of mandarin (Citrus reticulata Blanco), sweet orange [Citrus sinensis (L.) Osb.], and trifoliate orange [Poncirus trifoliata (L.) Raf.] were found to have adventitious juice vesicles originating from their exocarp (peel). Several hundred green vesicles may be initiated from curvilinear stylar peel depressions of immature fruit. These vesicles develop similarly to juice vesicles from the endocarp except that, as the fruit matures, exocarp adventitious vesicles die prematurely and degenerate into a fruit surface blemish. Evidence suggests that juice vesicles and oil glands are homologous and merit reconsideration in ontological studies.
\end{abstract}

Citrus fruit is a berry composed of a unique carpel structural arrangement referred to as a hesperidium (Bartholomew and Reed, 1943; Ford, 1942; Swingle and Reece, 1967). Structurally, citrus fruit consists of the flavedo (exocarp or peel), the albedo (mesocarp), and the pulp (endocarp). The exocarp is the fruit's epidermis and consists of several layers of cells within which occur the oil glands. The outermost cells are heavily cutinized. The albedo consists of white, thinwalled parenchyma cells and contains most of the fruit's vascular bundles. The pulp is composed of the segments, which consist of the juice vesicles and the central axis (Ford, 1942). Juice vesicles, endocarpal protuberances initiated during early fruit growth, de-

Received for publication 15 July 1991. Accepted for publication 24 Feb. 1992. Mention of a trademark, proprietary product or vendor does not constitute approval or guarantee of the product by the U.S. Dept. of Agriculture, and does not imply its approval to the exclusion of other products that may also be suitable. We thank George Yelenosky and the late John B. Carpenter for critically reading the manuscript. The cost of publishing this paper was defrayed in part by the payment of page charges. Under postal regulations, this paper therefore must be hereby marked advertisement solely to indicate this fact.

'Research Geneticist.

${ }^{2}$ Microbiological Research Technician. velop into mature vesicles with characteristic multicellular thread-like stalks and spindleshaped multicellular bodies. Juice vesicles occur in all the genera (e.g., Citrus, Fortunella, and Poncirus) of the subtribe Citrinae, subfamily Aurantioideae, family Rutaceae (Swingle and Reece, 1967), and have always been considered unique to the endocarpal regions of the hesperidium, i.e., the adaxial side of the carpel (Bartholomew and Reed, 1943; Ford, 1942; Swingle and Reece, 1967). However, in this report, we describe adventitious juice vesicle structures arising from the exocarp of the fruit, i.e., the abaxial side of the carpel.

Fruit were examined in 1987, 1988, and 1989 from 5- to 9 -year-old trees of $>100$ species and several hundred cultivars grown in the Citrus Variety Collection at the Univ. of California, Riverside. Fruits examined ranged from 30 to 310 days old after flower opening. In a separate study in 1988, a single examination was conducted with 150-dayold fruits from 15-year-old 'Fairchild' mandarin trees grown in a commercial grove located in the Coachella Valley. Twenty to 100 fruits were examined on branches oriented in various geographical directions.

Fruit stylar sections were placed in 3\% glutaraldehyde and embedded in Polaron glycol methacrylate polymer plastic for histological examination. Specimens were sectioned at $3 \mu \mathrm{m}$ and stained with $0.1 \%$ 

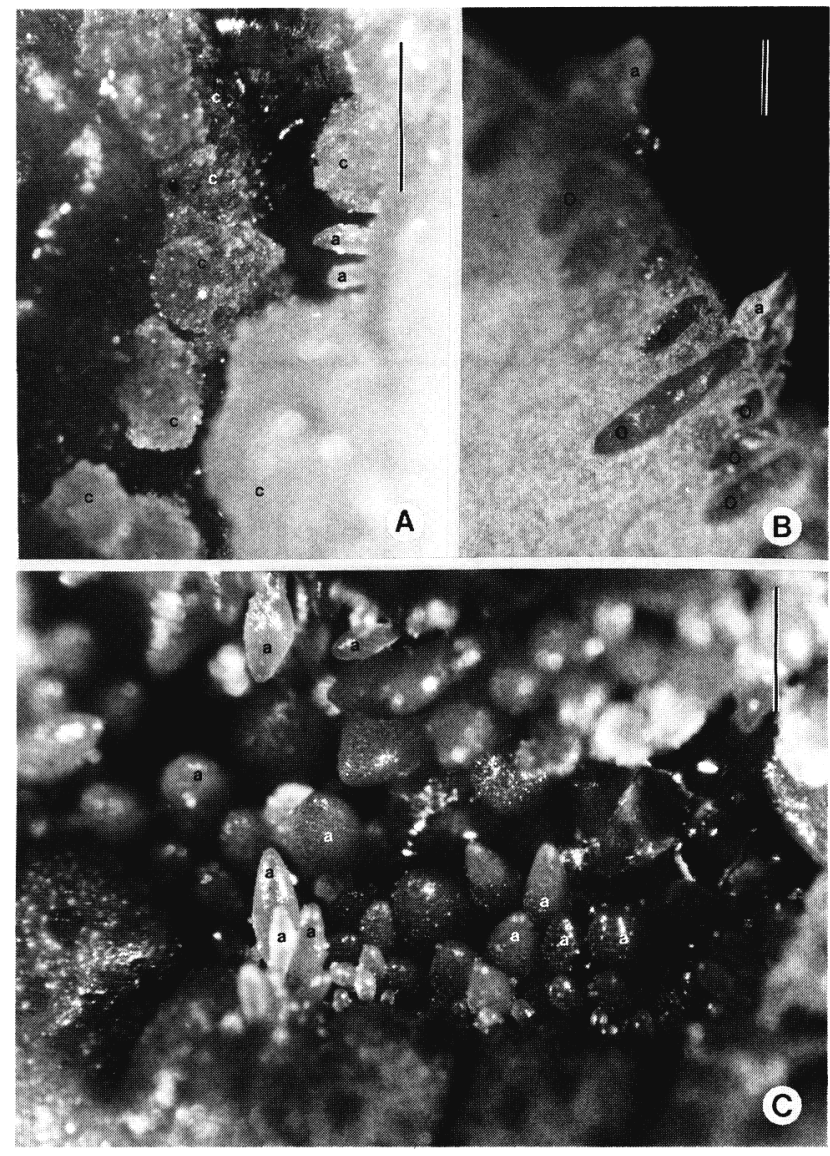

Fig. 1. Examples of adventitious juice vesicles produced from exocarp of 'Fuzzy Valencia' orange. (A) Adventitious juice vesicles produced from stylar depression in 90-day-old fruit. Note the occurrence of callus formation from the stylar depression as well as club-shaped vesicle structures (bar = $1 \mathrm{~mm}$ ). Note the occurrence of callus. (B) Adventitious vesicles originating from nondepression peel regions. Note the close association of the subepiderminal oil gland at the base of juice vesicles (bar $=1 \mathrm{~mm}$ ). (C) Adventitious juice vesicles produced in the stylar depression of a 150-day-old fruit (bar $=0.5 \mathrm{~mm}$ ). Vesicles in various stages of development occur adjacent to each other $(\mathrm{a}=$ adventitious juice vesicle, $\mathrm{c}=$ callus, $\mathrm{o}=$ oil gland).

toluidine blue. Photographs were made with Kodak Plus-X film with a Kodak \#25 Wratten gelatin filter. Fruit portions were also examined with a scanning electron microscope (SEM), where vesicles and peel tissues were mounted fresh on stubs covered with double-stik tape and viewed directly with a JEOL-35C SEM (Jeol, Tokyo) at $5 \mathrm{kV}$. SEM photographs were made with Polaroid type 55 black-and-white film.

Exocarp adventitious juice vesicles were found only in one cultivar each of three species: $C$. reticulata cv. Fairchild, C. sinensis cv. Fuzzy Valencia, and P. trifoliata cv. Rich 16-6. Adventitious juice vesicle initiation and development were similar in all three species, we describe in detail 'Fuzzy Valencia' adventitious juice vesicle production, based on the examination of 275 fruit. Adventitious juice vesicles from 'Fuzzy Valencia' were first observed in May or June when the fruit was $\approx 90$ to 120 days old and originated from a peculiar depression near the stylar end of the fruit (Figs. 1-4). These depressions varied in depth (2 to $4 \mathrm{~mm}$ ), width (2 to $5 \mathrm{~mm}$ ), and circumference among fruits; in some cases, the depressions encircled the stylar end of the fruit, while in others only a quarter- or half-circle depression was pro- duced (Fig. 3). There was no correlation between size of depression on the fruit and geographical location on the tree. About 95\% of the fruit produce these stylar depressions, which provided the location for the adventitious exocarp vesicles to form (Fig. 3). There was great variation in terms of fruit with vesicle-producing depressions. In some cases, fruits produced only minute depressions containing only a few early vesicle forms. Often, these vesicles ceased development and died within 30 days after initiation. In other oases, fruits produced depressions that persisted and enlarged considerably and contained numerous vesicles that were up to $5 \mathrm{~mm}$ long. Also, the exocarp vesicles from depressions varied in their longevity, with some degenerating and dying faster than neighboring vesicles. Adventitious juice vesicles may also originate from the stylar latitudes not associated with the original depression area of the fruit (Figs. 1B and 2). This condition occurs in $\approx 5 \%$ of the fruit, but only after the stylar depression was formed. In fruit $\approx 150$ days old, depressions may develop on the stem end of the fruit from which exocarp vesicles subsequently emerge, paralleling the stylar depression situation (Fig. 2). Formation of a stem depression only occurs following the

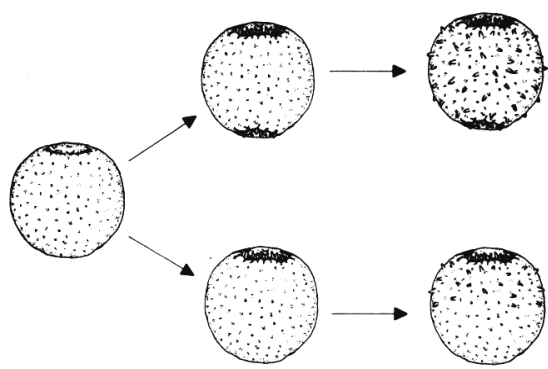

Fig. 2. Diagram of adventitious juice vesicle production in 'Fuzzy Valencia' orange. Fruit with stylar depression provides initial pathway for adventitious exocarp vesicle production. As shown in the bottom pathway, the original stylar depression gives rise to an enlarged depression with larger exocarp vesicles or, as in some fruit vesicles, may also originate from stylar latitudes. In the top pathway, exocarp vesicles are produced from both stylar and stem depressions or, in some, exocarp vesicles may also originate in all latitudes. All of these fruit types may occur simultaneously on the same tree.

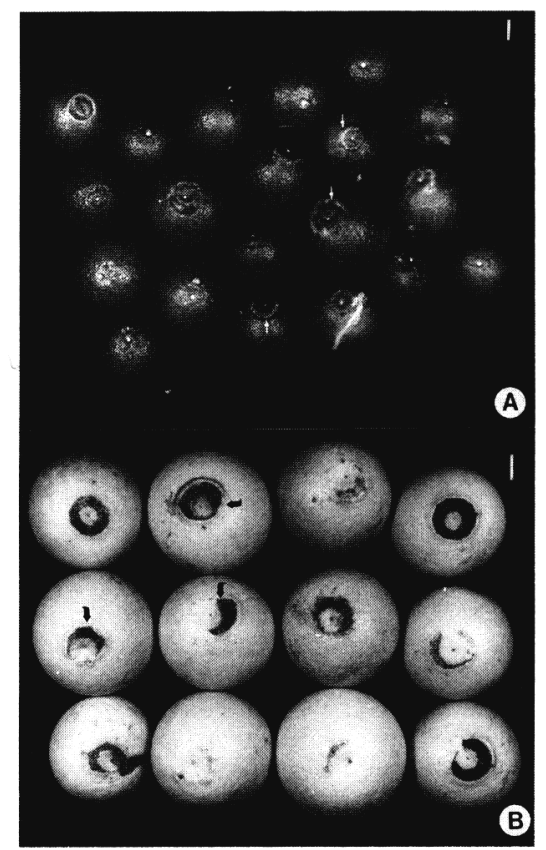

Fig. 3. Surface stylar morphology of 150 - and 210-day-old fruits of 'Fuzzy Valencia' orange. (A) Stylar end of green 150-day-old fruits, (B) stylar end of orange 200-day-old fruits. Note arrows pointing out stylar peel depressions, the location of adventitious juice vesicles (bar $=$ $10 \mathrm{~mm})$.

formation of the stylar depression (Fig. 2). This situation occurs in $\approx 30 \%$ of the fruit. Also, in $<1 \%$ of the fruit, the entire surface of the fruit produces vesicles, following the sequential formation of the stylar and then stem depressions (Fig. 2). Exocarp vesicles initiate as bulges or protuberances and are green. Both stylar and stem depressions were restricted to the peel region, and there was no physical connection to the internal endocarp (Figs. $1 \mathrm{~A}, \mathrm{C}$ and $4 \mathrm{~A}-\mathrm{C}$ ).

Exocarp adventitious juice vesicles, derived from depressions, resemble the natu- 


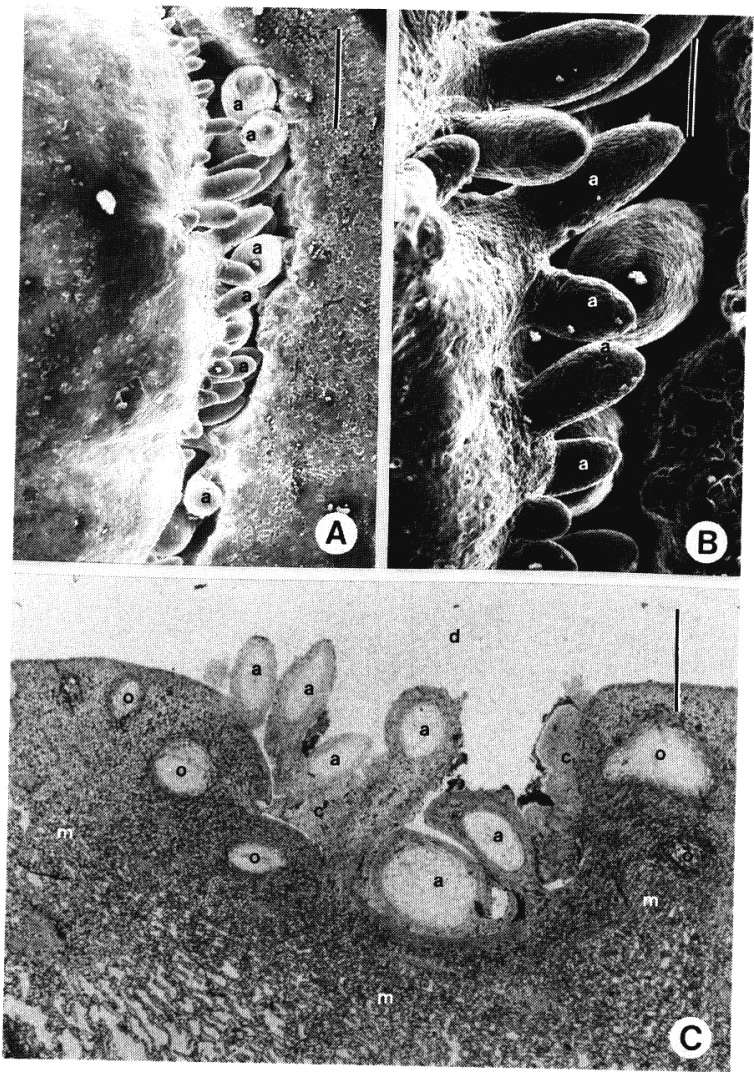

Fig. 4. Scanning electron microscopy (A and B) and histological photographs (C) of 'Fuzzy Valencia' orange juice vesicles produced from the stylar end of 150-day-old fruits. (A) Nonsynchronous initiation of peel adventitious juice vesicles from a stylar depression (bar $=0.75 \mathrm{~mm}$ ). (B) Close up of $(\mathbf{A})$ (bar $=0.25 \mathrm{~mm}$ ). (C) Histological section of exocarp stylar portion. Note the physical similarity of adventitious juice vesicles and oil glands in terms of size and shape. The oil gland demarcation occurs where adventitious juice vesicle formation begins ( $a=$ adventitious juice vesicle, $\mathrm{c}=$ callus, $\mathrm{d}=$ stylar depression, $\mathrm{m}=$ mesocarp, $\mathrm{o}=$ oil gland, bar $=1 \mathrm{~mm}$ ).

rally occurring endocarp vesicles produced within the fruit in terms of size and mode of development (Figs. 1C and 4 A-C). Similar stages of vesicle development are observed from the endocarp and exocarp tissues: initial bulges and club, conical, and elliptical shapes. Also, adventitious vesicles at various stages of development may exist simultaneously (Figs. 1C and 4A-C) (Bartholomew and Reed, 1943; Ford, 1942). Endocarp and exocarp vesicles change from green to orange as the fruit matures. Persistent mature exocarp vesicles degenerate early in their development (as noted above) and invariably die in the late summer and early fall (Fig. 3). In contrast, endocarp vesicles persist and continue to accumulate juice (Bartholomew and Reed, 1943; Ford, 1942). Those fruit occurring on the outside canopy of the tree produced shorter-lived exocarp vesicles than those within the canopy. Presumably, the greater exposure to the harsher environment (e.g., sunlight, temperature, and wind) shortens the exocarp vesicle life span.

The tissue of these peculiar depressions was the source of adventitious vesicles. The number of adventitious vesicles produced depended on the area of these depressions. Generally, up to 400 vesicles were initiated from these depressions. Vesicles were initiated as bulges from both the edges and the interior of these depressions (Figs. $1 \mathrm{~A}, \mathrm{C}$ and 4 A-C). Associated with these depressions is the formation of callus tissue, especially in immature fruit (Figs. 1A and 4C). Wound callus occurred only in the depressions. The formation of callus from a nonwounded portion of the fruit or plant is unusual. As callus is usually associated with an externally inflicted wound, the depression may be a type of wound. Oil glands were absent in the innermost regions of depressions (Fig. 4C). Oil glands were conspicuously absent beneath areas of the depression where prolific adventitious juice vesicles were initiated. This situation parallels the absence of oil glands in the endocarp tissue where juice vesicles occur.

Adventitious vesicles initiated from the nondepression regions invariably were closely associated with subepidermal oil glands, suggesting a transitional form of oil glandvesicle structure (Fig. 1B). An oil gland was found to occur at the base of every nondepression surface peel vesicle. This type of adventitious juice vesicle was morphologically dissimilar to the adventitious juice vesicles produced in the depressions where oil glands were lacking beneath the depression vesicles.

The production of adventitious juice vesicles results in a fruit peel blemish, consist- ing of circumscribed necrotic tissue composed of minute brown protuberances located at the stylar and stem portions of the fruit. Although these blemishes are commercially undesirable, they do not appear to affect the juice quality in the endocarp. Therefore, cultivars that have developed this condition in the past have been intentionally eliminated by growers and breeders. Two of the three cases of adventitious vesicle peel production occur in cultivars maintained in the Riverside germplasm collection. 'Fairchild' mandarin and 'Fuzzy Valencia' have a common mandarin ancestry. 'Fairchild' mandarin originated from a cross of 'Clementine' mandarin x 'Orlando' tangelo (Swingle and Reece, 1967). 'Fuzzy Valencia' originated in the early 1940s as a 'Valencia' orange bud sport in Ontario, Calif. Oranges presumably originated from a mandarin $\mathrm{x}$ pummelo cross (Swingle and Reece, 1967). Trifoliate 'Rich 16-6' was procured as a chance selection from Arizona in the 1930s. Poncirus crosses freely with Citrus to produce hybrids (Swingle and Reece, 1967). Trifoliate 'Rich 16-6' possibly may contain the mandarin genetics that give rise to external peel vesicles, although no evidence exists that this is actually the case.

Oddly, 'Fairchild' mandarin grown at Riverside did not exhibit the exocarp juice vesicle phenomenon, while 'Fairchild' mandarins grown in the Coachella Valley consistently produced these vesicles. Either this difference is environmentally induced in some cultivars, since Riverside has a Mediterranean/chaparral climate while Coachell Valley has a desert climate, or two separate 'Fairchild' mandarin cultivars co-exist in southern California.

Oil glands are found on all surface parts of the citrus plant and flower, with the exception of the endocarp, which only produces juice vesicles. Bonavia (1888) suggested that juice vesicles are modified oil glands. The physical development of oil glands and juice vesicles is similar, except that oil glands are produced within the exocarp tissue and juice vesicles are produced as proliferations growing into the locule cavity. Davis (1932) found that most Citrus spp. and cultivars contain oil deposits in their juice vesicles. These juice vesicle oil droplets may be a vestigial characteristic of a modified oil gland. Ford (1942), however, concluded that juice vesicles and oil glands are not homologous structures. Swingle and Reece (1967) classify the subtribe Citrinae, based on the occurrence of juice vesicles into 13 genera and 65 species. Only the genera Citrus and Fortunella contain edible vesicles while vesicles found in other genera are inedible due to their excessive oil and resin content.

We suggest that exocarp oil glands sometimes are modified to produce juice vesicles and, conversely, infer that endocarpal juice vesicles are derived from modified oil glands. In light of the observations presented in this study, we conclude that juice vesicles and oil glands are homologous and should be so considered in future ontological studies. 


\section{Literature Cited}

Bartholomew, E.T. and H.S. Reed. 1943. General morphology, histology and physiology, $\mathrm{p}$. 669-717. In: H.J. Webber and L.D. Batchelor feds.). The citrus industry. Univ. of California. Berkeley.
Bonavia, E. 1888. The cultivated oranges and lemons etc. of India and Ceylon. W.H. Allen \& Co., London. p. 175-193.

Davis, W.B. 1932. Deposits of oil in the juice sacs of citrus fruits. Amer. J. Bot. 19:101-105. Ford, E.S. 1942. The anatomy and histology of the Eureka Lemon. Bot. Gaz. 104:288-305.

Svingle, W.T. and P.C. Reece. 1967. The botany of Citrus and its wild relatives, p. 190-430. In: W. Reuther, H.J. Webber, and L.D. Batchelor (eds.). The citrus industry, vol. 1. Univ. of California, Berkeley. 